\title{
Phakic Intraocular Lenses in Keratoconus
}

\author{
1Jorge L Alio, ${ }^{2}$ Pablo Sanz-Díez
}

\begin{abstract}
Purpose: To discuss and summarize the indications, contraindications and results in refractive surgery for keratoconus.
\end{abstract}

Summary: Keratoconus is an ectatic corneal disease characterized by a progressive corneal thinning and irregular astigmatism that negatively impact in the visual function and the optical quality of the patients. The refractive surgery in keratoconus has been discussed by several authors. The two primary lines of action are phakic lens implantation and corneal tissue ablation using photorefractive keratectomy. The use of phakic intraocular lenses (IOLs) to correct myopia and compound myopic astigmatism associated with keratoconus is gaining popularity.

Recent findings: The use of phakic IOLs to correct myopia and compound myopic astigmatism associated with keratoconus is gaining popularity. According to a recent study by our group the safety of this procedure in visual terms is high (post-CDVA/ pre-CDVA $=1.19 \pm 0.29$ ). It is also an effective operation (postUDVA/pre-CDVA $=0.90 \pm 0.26$ )

Keywords: Corneal ectasia, Keratoconus, Phakic intraocular lens, Refractive surgery.

How to cite this article: Alio JL, Sanz-Díez P. Phakic Intraocular Lenses in Keratoconus. Int J Kerat Ect Cor Dis 2015;4(3): 103-106.

Source of support: Nil

Conflict of interest: None

\section{INTRODUCTION}

Keratoconus is an ectatic corneal disorder characterized by progressive corneal thinning that result in corneal protrusion, irregular astigmatism and decreased vision. This corneal disorder induces myopia and astigmatism in both regular and irregular forms, often leading to marked visual impairment.

The use of keratoconus surgery for refractive purposes has been discussed by several authors in

\footnotetext{
${ }^{1}$ Professor and Chairman, ${ }^{2}$ Research Scientist

${ }^{1}$ VISSUM, Alicante, Ophthalmology Division, Miguel Hernández University, Elche, Alicante, Spain

${ }^{2}$ Ophthalmology Division, Miguel Hernández University, Elche Alicante, Spain

Corresponding Author: Jorge L Alio, Professor and Chairman, VISSUM, Alicante, Ophthalmology Division, Miguel Hernández University, Elche, Alicante, Spain, e-mail: jlalio@ vissum.com
}

medical literature. The two primary lines of action are phakic lens implantation ${ }^{1-6}$ and corneal tissue ablation using photorefractive keratectomy. The latter technique is usually combined with cross-linking. ${ }^{7-11}$

Both are normally used in patients with forme fruste or frank, but stable, keratoconus ${ }^{6}$ and are not the techniques of choice in progressive patients, although there are some studies along these lines. ${ }^{8,12,13}$

These techniques have also been used in combination with intrastromal corneal ring segment (ICRS) implantation. ${ }^{14,15}$

In accordance with our research, we believe that this type of surgery should be reserved solely for stable patients. If one (or several) of the circumstances described below occurs in an interval of less than 1 year, keratoconus is considered progressive:

- Increase in astigmatism of 1.0 D or more

- Significant changes in the orientation of refractive axes

- Increase of 1.0 D or more in the optical power of the steepest corneal meridian

- Decrease of 25 microns or more in corneal thickness

\section{INTRAOCULAR REFRACTIVE SURGERY}

The use of phakic intraocular lenses (IOLs) to correct myopia and compound myopic astigmatism associated with keratoconus is gaining popularity.

This type of surgery presents a complicated clinical environment due to:

- Abnormal cornea with potential progressive deterioration.

- Very important level of higher order aberrations due to corneal irregularity limits the potential eye potential for best spectacle corrected visual acuity.

- Some aberrations, especially important: Very negative spherical aberration, (-0.35 to -1.50$)$, high coma (from 1 to $>5$ microns).

- Special optical considerations: Corneal vertex, visual axis and pupillary axis, not coincident at all in keratoconus.

The use of phakic lenses has advantages, such as efficient and stable ametropia compensation, preservation of accommodation, centered and rotational stability not dependent on corneal morphology, retinal image magnification in patients with high myopia and reversibility in the event of failure. 
Table 1: Indications, relative indications and contraindications for phakic lens implantation in keratoconus

\begin{tabular}{|c|c|c|}
\hline Indications & Relative indications & Contraindications \\
\hline $\begin{array}{l}\text { Corneal topography stable and age } \\
>35-40 \text { years }\end{array}$ & $\begin{array}{l}\text { Keratoconus, stable following CCL } \\
\text { (topography and refraction) }\end{array}$ & $\begin{array}{l}\text { Progressive keratoconus, unstable } \\
\text { corneas }\end{array}$ \\
\hline $\begin{array}{l}\text { Good spectacle-corrected visual acuity } \\
(>0.6 ; 20 / 30)\end{array}$ & Following DALK or PKP & Young patients (<25 years old?) \\
\hline $\begin{array}{l}\text { Stable refraction for about } 2 \text { years. } \\
\text { Spherical equivalent greater than }-2.75 \mathrm{D}\end{array}$ & $\begin{array}{l}\text { Moderately good vision but with poor } \\
\text { tolerance to glasses or contact lenses }\end{array}$ & $\begin{array}{l}\text { Highly aberrated eyes (total } \mathrm{HOA}>3 \\
\text { microns) with poor best spectacle } \\
\text { corrected visual acuity }(<0.5)\end{array}$ \\
\hline $\begin{array}{l}\text { Absence of clinically significant irregular } \\
\text { astigmatism. We consider irregular } \\
\text { astigmatism to be clinically significant } \\
\text { when there is a difference greater than } \\
1 \text { line of corrected vision between the } \\
\text { vision obtained with glasses and the vision } \\
\text { obtained with hard contact lenses }\end{array}$ & $\begin{array}{l}\text { Anisometropia with adequate refractive } \\
\text { anatomy and stable refraction }\end{array}$ & \\
\hline
\end{tabular}

Negative effects of phakic lens implantation include accelerated endothelial cell loss, cataract formation, pupil ovalization, lens rotation or decentration, photic phenomena and retinal detachment in isolated cases.

\section{Implantation Criteria}

Based on our experience and that described in medical literature, we believe the following criteria should be met for phakic lens implantation in keratoconus (Table 1).

According to a recent study by our group with the largest number of case studies on phakic lens implantation in keratoconus reported to date, ${ }^{6}$ the safety of this procedure in visual terms is high (post-CDVA/pre$\mathrm{CDVA}=1.19 \pm 0.29$ ). It is also an effective operation (post$\mathrm{UDVA} /$ pre-CDVA $=0.90 \pm 0.26$ ). In fact, many patients stopped wearing glasses after phakic lens implantation. These results are roughly consistent with those reported by other authors. ${ }^{1-5}$

It is also interesting to note that, based on the results of this study, implantation of a foldable lenses can be as safe and effective as implantation of a hard lens. The following models were studied: foldable Artiflex lens

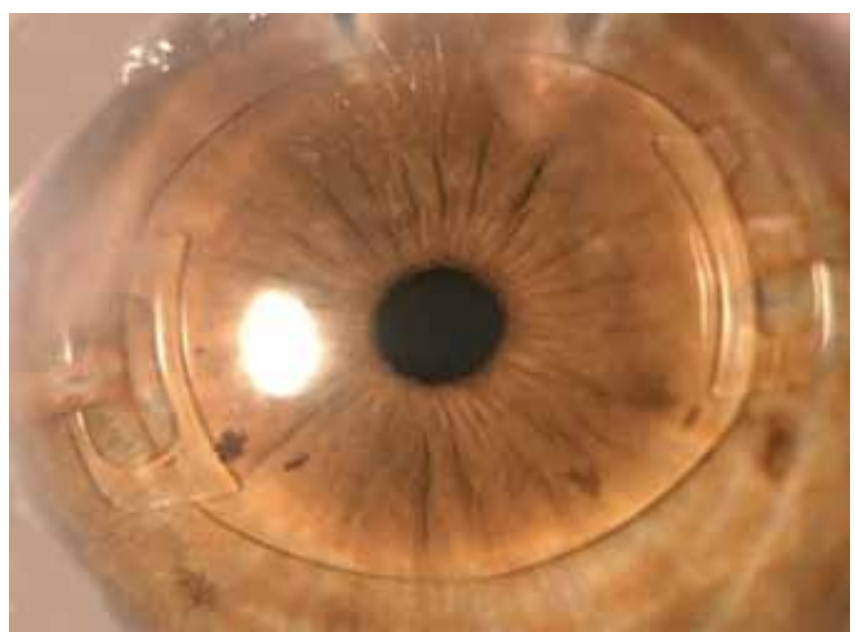

Fig. 1: Artiflex (Ophtec, Netherlands)
(Ophtec, Netherlands) (Fig. 1) and the ICL [implantable collamer lens (ICL), STAAR Surgical, USA] (Fig. 2).

This result is particularly interesting, because flexible lenses can be inserted and removed through smaller incisions thanks to their flexibility.

We recommend that, whenever possible, implantation be performed using this type of microincision surgery (with incision of 1.8-2.00 $\mathrm{mm}$ ) to ensure that the ectatic process is not affected as a result of the operation. It has been widely demonstrated that the use of this type of incision causes minimal alternations in the cornea. ${ }^{16,17}$

\section{CORNEAL REFRACTIVE SURGERY}

Corneal ablation for the treatment of keratoconus has been discussed by several authors. While the precision obtained in ablating the corneal surface with laser ablation may be very high in normal corneas, it is unclear whether the same occurs with keratoconic patients due to pre-existing corneal asymmetry and to the reduced reliability and repeatability of keratometry measurements in such patients. ${ }^{18}$ In addition, ablating corneal tissue in patients whose corneal biomechanics and pachymetry

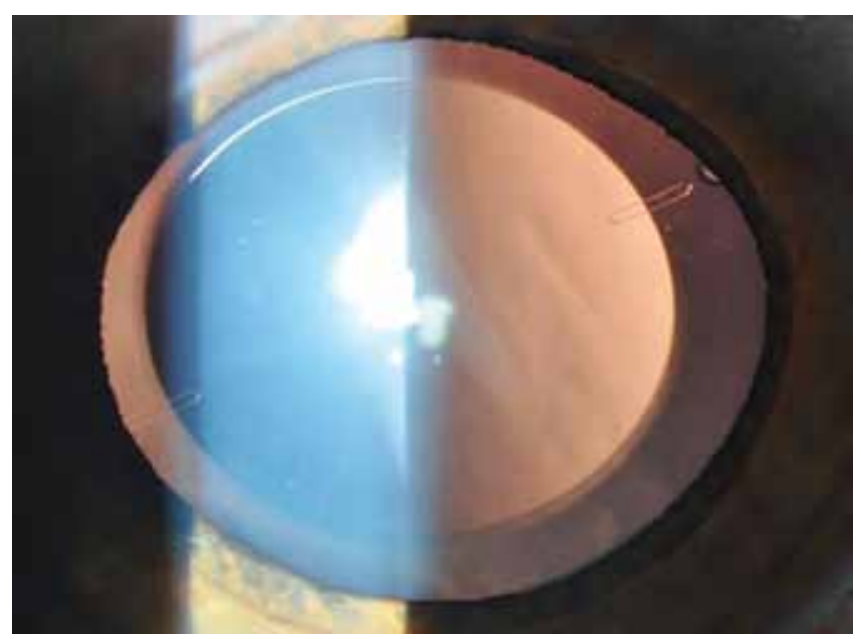

Fig. 2: ICL (STAAR Surgical, USA) 
are already altered are a risk factor to bear in mind. Obviously, unlike phakic lenses, this technique cannot be used to treat high levels of myopia (which are frequent in keratoconus), because the ablation is so deep in these cases. Furthermore, this technique is not reversible.

We therefore believe this is not the technique of choice and should at least be combined with cross-linking.

Our experience shows that it is a safe technique $(1.03 \pm$ $0.08)$ with a high degree of effectiveness $(0.91 \pm 0.18)$, but we have only been able to confirm these results in the short term. Moreover, we detected some cases in which the ectasia became progressive. Hence, the need for combined use with cross-linking and, for more cases, studies with longer follow-up.

Interestingly, regarding the use of this surgery on keratonic eyes, some authors like Vinciguerra et $\mathrm{al}^{19}$ suggest using corneal topography data before epithelial removal to avoid the masking effect over the stroma that may occur in keratoconus. This is obviously an inconvenient practice for the patient, but a well-founded one in our opinion.

Lastly, regarding the ablation profile to use, we think it is better to use wavefront-guided ablation as opposed to topography-guided ablation. This is because with the latter technique the operation is conducted based on the aberrometric profile of the anterior corneal surface. As it has been widely reported in the literature, high internal astigmatism is common in keratoconic eyes due to large disparities between the anterior and posterior corneal surfaces. ${ }^{20,21}$ For this reason, we believe it is better to use a customized wavefront profile.

In any case, as stated above, we do not consider PRK on its own to be the technique of choice in keratoconus, despite the high efficacy rates obtained (in a small series of only 21 eyes), due to doubts concerning long-term stability. ${ }^{22}$

\section{CONCLUSION}

- Phakic intraocular lenses offer excellent visual results in keratoconus stable patients.

- The keratometric stability was confirmed during the follow-up (mean FU = 15 months).

- The use of PIOLs can be combined with other procedures, such as ICRS implantation or cross-linking.

- High safety levels were achieved with both type of lenses, Artiflex $(1.22 \pm 0.33)$ and ICL $(1.21 \pm 0.28)$. No significant difference was found ( $p=0.588$, MannWhitney test).

- Better values of the efficacy index ( $p=0.058$, MannWhitney test) were found for the iris-fixated model $(0.96 \pm 0.22)$ compared with the posterior chamber model $(0.88 \pm 0.28)$.

\section{REFERENCES}

1. Sedaghat M, Ansari-Astaneh MR, Zarei-Ghanavati M, Davis SW, Sikder S. Artisan iris-supported phakic IOL implantation in patients with keratoconus: a review of 16 eyes. J Refract Surg 2011 Jul;27(7):489-493.

2. Kamiya K, Shimizu K, Kobashi H, Komatsu M, Nakamura A, Nakamura T, Ichikawa K. Clinical outcomes of posterior chamber toricphakic intraocular lens implantation for the correction of high myopic astigmatism in eyes with keratoconus: 6-month follow-up. Graefes Arch Clin Exp Ophthalmol 2011 Jul;249(7):1073-1080.

3. Venter J. Artisan phakic intraocular lens in patients with keratoconus. J Refract Surg 2009 Sep;25(9):759-764.

4. Kurian M, Nagappa S, Bhagali R, Shetty R, Shetty BK. Visual quality after posterior chamber phakic intraocular lens implantation in keratoconus. J Cataract Refract Surg 2012 Jun;38(6):1050-1057.

5. Leccisotti A, Fields SV. Angle-supported phakic intraocular lenses in eyes with keratoconus and myopia. J Cataract Refract Surg 2003 Aug;29(8):1530-1536.

6. Alió JL, Peña-García P, Abdulla F, Zein G, Abumustafa S. Comparison of iris-claw and posterior chamber collagen copolymer phakic intraocular lenses in keratoconus. J Cataract Refract Surg 2014 Mar;40(3):383-394.

7. Kanellopoulos AJ, Binder PS. Collagen cross-linking (CCL) with sequential topography-guided PRK; a temporizing alternative for keratoconus to penetrating rusta lasty. Cornea 2007 Aug;26(7):891-895.

8. Krueger RR, Kanellopoulos AJ. Stability of simultaneous topography-guided photorefractive keratectomy and riboflavin/ UVA cross-linking for progressive keratoconus: case reports. J Refract Surg 2010 Oct;26(10):S827-832.

9. Kymionis GD, Kontadakis GA, Kounis GA, Portaliou DM, Karavitaki AE, Magarakis M, Yoo S, Pallikaris IG. Simultaneous topography-guided PRK followed by corneal collagen cross-linking for keratoconus. J Refract Surg 2009 Sep;25(9):S807-811.

10. Kanellopoulos AJ. Comparison of sequential vs same-day simultaneous collagen cross-linking and topography-guided PRK for treatment of keratoconus. J Refract Surg 2009 Sep; 25(9):S812-818.

11. Stojanovic A, Zhang J, Chen X, Nitter TA, Chen S, Wang Q. Topography-guided transepithelial surface ablation followed by corneal collagen cross-linking performed in a single combined procedure for the treatment of keratoconus and pellucid marginal degeneration. J Refract Surg 2010 Feb; 26(2):145-152.

12. Güell JL, Morral M, Malecaze F, Gris O, Elies D, Manero F. Collagen cross-linking and toric iris-claw phakic intraocular lens for myopic astigmatism in progressive mild to moderate keratoconus. J Cataract Refract Surg 2012 Mar;38(3):475-484.

13. Alessio G, L'abbate M,Sborgia C, La Tegola MG. Photorefractive keratectomy followed by cross-linking versus cross-linking alone for management of progressive keratoconus: two-year follow-up. Am J Ophthalmol 2013;155(1):54-65.

14. Navas A, Tapia-Herrera G, Jaimes M, Graue-Hernández EO, Gomez-Bastar A, Ramirez-Luquín T, Ramirez-Miranda A. Implantable collamer lenses after intracorneal ring segments for keratoconus. Int Ophthalmol 2012 Oct;32(5):423-429.

15. Moshirfar M, Fenzl CR, Meyer JJ, Neuffer MC, Espandar L, Mifflin MD. Simultaneous and sequential implantation of intacs and verisysephakic intraocular lens for refractive improvement in keratectasia. Cornea 2011 Feb;30(2):158-163. 
16. Denoyer A, Denoyer L, Marotte D, et al. Intraindividual comparative study of corneal and ocular wavefront aberrations after biaxial microincision versus coaxial smallincision cataract surgery. Br J Ophthalmol 2008;92(12): 1679-1684.

17. Mojzis P, Piñero DP, Studeny P, et al. Comparative analysis of clinical outcomes obtained with a new diffractive multifocal toric intraocular lens implanted through two types of corneal incision. J Refract Surg 2011;27(9):648-657.

18. McMahon TT, Anderson RJ, Roberts C, et al. CLEK Study Group. Repeatability of corneal topography measurement in keratoconus with the TMS-1. Optom Vis Sci 2005;82(5): 405-415.

19. Vinciguerra P, Munoz MI, Camesasca FI, Grizzi F, Roberts C. Long-term follow-up of ultrathin corneas after surface retreatment with phototherapeutic keratectomy. J Cataract Refract Surg 2005;31(1):82-87.

20. Alió JL, Piñero DP, Alesón A, Teus MA, Barraquer RI, Murta J, Maldonado MJ, Castro de Luna G, Gutiérrez R, Villa C, Uceda-Montanes A. Keratoconus-integrated characterisation considering anterior corneal aberrations, internal astigmatism, and corneal biomechanics. J Cataract Refract Surg 2011; 37(3):552-568.

21. Piñero DP, Alió JL, Tomás J, Maldonado MJ, Teus MA, Barraquer RI. Vector analysis of evolutive corneal astigmatic changes in keratoconus. Invest Ophthalmol Vis Sci 2011 June 8;52(7):4054-4062.

22. Peña-García P. Vectorial analysis of astigmatic correction in stable keratoconus. PRK vs PIOLs. JCRS-2014-081, Version 1 (Sent). 